\title{
RASIONALISME RENE DESCARTES
}

\section{NGISMATUL CHOIRIYAH}

Dosen Pada Fakultas Agama Islam Universitas Muhammadiyah Palangkaraya

\begin{abstract}
Rasionalisme is assumption where mind is the only resource to overcome truth which is beyond sense.

Rene Descarates found method to make realistic philosophic and logic by doubtful everyting or implementing doubtful method which mean doubtful should include all informations we have.

According to Descartes mind is the stand-alone substance in term I think I exist, mind is immaterial. Mind is conscious and its character is to think and body is part of matery. Matery character is immensity.
\end{abstract}

Key words : rationalization, Rene Descartes

\section{ABSTRAK}

Rasionalisme adalah paham yang menganggap bahwa pikiran akal merupakan satu-satunya dasar untuk memecahkan kebenaran yang lepas dari jangkauan indera.

Rene Descartes menemukan metode agar hasil dari mempelajari filsafat benar-benar logis yaitu dengan menyangsikan segala-galanya atau menerapkan metode keragu-raguan artinya keragu-raguan harus meliputi seluruh pengetahuan yang dimilki.

Menurut Descartes akal adalah substansi yang berdiri sendiri dengan istilah aku berfikir maka aku ada (cogito ergo sum), akal itu immaterial. Akal adalah kesadaran dan sifatnya adalah berfikir, sedangkan tubuh adalah bagian dari alam materi. Sifat materi adalah keluasan.

Kata kunci : rasionalisasi, Rene Descartes

\section{PENDAHULUAN}

Rasionalisme adalah salah satu bagian dalam penelaahan ilmu filsafat. Secara umum rasionalisme dipahami sebagai cabang yang mempelajari sumber-sumber watak dan kebenaran pengetahuan yang diperoleh dari penalaran akal manusia.

Rasionalisme adalah paham filsafat yang menyatakan bahwa akal (reason) adalah alat terpenting untuk memperoleh pengetahuan. Menurut aliran rasionalis, suatu pengetahuan diperoleh dengan cara berfikir.

Dalam kaitannya dengan pembentukan ilmu pengetahuan, rasionalisme menarik pemikiran-pemikiran empiris tersebut ke dalam pernyataan-pernyataan yang logis serta mengesampingkan pemikiran yang bersifat metafisika atau yang berada di luar jangkauan manusia untuk memperoleh nilai yang lebih aplikatif bagi kehidupan manusia.

Filsafat rasionalisme ini dimotori oleh Rene Descartes yang bergelar "Bapak Filsafat Modern" dan kemudian dikembangkan oleh Spinoza (16321677 M) dan Leibniz (1646-1716 M). Untuk lebih jelas dan mendalamnya pengetahuan tentang rasionalisme maka dalam makalah ini, penulis ingin memaparkan mengenai rasioanilime khususnya dari Rene Descartes. 


\section{RIWAYAT HIDUP RENE DESCARTES}

Descartes lahir pada tahun 1596. Dia dilahirkan di francis, ayahnya seorang anggota parlemen Inggris, ibunya meninggal ketika Rene berumur satu tahun, ayahnya menikah lagi kemudian Descartes dipelihara oleh neneknya, sejak itu ia tidak pernah melihat ayahnya lagi.

Pada tahun $1612 \mathrm{M}$ ia pergi ke Paris Prancis dan di sana ia mendapatkan kehidupan social yang menjemukan hingga ia mengucilkan diri ke Faoubourg Sain German untuk mengerjakan ilmu ukur, ia tidak pernah menikah tetapi punya anak bersama dengan pembantunya, namun anak tersebut meninggal dan menyebabkan kesedihan yang mendalam.

Pada tahun 1617, Descartes masuk ke tentara Belanda dan tinggal di negeri kincir angin selama dua tahun, di sana ia mengalami suasana damai dan tentram sehingga ia dapat mengerjakan renungan filsafatnya. Tahun 1619 ia bergabung dengan tentara Bavaria dan selama musim dingin antara tahun 1619-1620 di kota ini ia mempunyai pengalaman yang kemudian dituangkan dalam buku pertamanya Descour de la Methode yang berarti uraian tentang metode (1637), yang isinya malukiskan perkembangan intelektualnya. Di dalam karya inilah, ia menyatakan ketidakpuasannya atas filsafat dan ilmu pengetahuan yang menjadi bahan penyelidikannya. Di dalam bidang ilmiah tidak ada sesuatupun yang dianggap pasti karena semua dapat dipersoalkan dan pada kenyataannya memang dipersoalkan juga.

Descartes adalah anak yang sangat cerdas, suka berfikir dan suka menyendiri. Pada waktu ayahnya meninggal dan saudara sekandungnya menikah ia tak mau dating. Pada umur 8 tahun ia masuk Royal College yang dikelola pastur-pastur Yesuit. la belajar di tempat itu selama 10 tahun. la mendapat pelajaran bahasa Yunani, latin, Francis, musik, drama, mengarang, bermain anggar, dan naik kuda. Pada tahun terakhir saat kuliyah ia belajar filsafat, moral, dan matematika, tetapi ilmu pengetahuan yang ia terima hanya menimbulkan keraguan dalam jiwanya kecuali matematika. Dan karena alas an kesehatannya lemah ia diperbolehkan terlambat kuliyah atau tidak megikuti kuliyah, meskipun demikian pada tahun 1616 pada umur 20 tahun ia berhasil memperoleh gelar ahli hukum.

Tahun 1621, Descartes berhenti dari medan perang dan setelah berkelana ke Italia, lalu ia menetap di Paris. Tiga tahun kemudian ia kembali masuk tentara, tetapi tidak lama ia keluar lagi dan akhirnya memutuskan untuk hidup di Negeri Belanda. Di sinilah ia menetap selama 20 tahun dalam iklim bebas berfikir.

Descartes menghabiskan sisa hidupnya di Swedia, tatkala ia memenuhi undangan ratu Cristine yang menginginkan pelajaran darinya yang diajarkan setiap jam lima pagi, menyebabkan Descartes jatuh sakit yang akhirnya meninggal pada tahun 1650 sebelum sempat menikah .

Karya-karya Rene Descartes yang terkenal adalah Descours de la method (1637), Meditationes de Prima Philosophia (1641), Taite des Passions (1649), Dioptrique, la Geometrie, les Meteores, Prinsipia, De la Formation du Foetus. 


\section{RASIONALISME RENE DESCARTES} (1596-1650 M)

Descartes adalah tokoh rasionalisme dalam filsafat modern. Sebelum membahas rasionalismenya Descartes ada baiknya diuraikan dulu pengertian rasionalisme.

Rasionalisme adalah faham filsafat yang mengatakan bahwa akal (reason) adalah alat terpenting untuk memperoleh pengetahuan, bahwa kebenaran tertinggi berada pada akal atau rasio manusia. Atau rasionalisme adalah sebuah anggapan mengenai teori pengetahuan yang menekankan akal atau rasio yang membentuk pengetahuan. Ini berarti bahwa sumbangan akal lebih besar dari pada indera. Rasionalisme atau gerakan rasionalis adalah doktrin filsafat yang menyatakan bahwa kebenaran haruslah ditentukan melalui pembuktian logika, dan analisis yang berdasarkan fakta, dari pada malalui iman, dogma,atau ajaran agama.

Kesimpulannya Rasionalisme adalah mengajarkan bahwa pengetahuan diperoleh dengan jalan berfikir.

Filosof tidak puas dengan filsafat scolastik yang pandangan-pandangannya saling bertentangan dan tidak ada kepastian disebabkan oleh miskinnya metode berfikir yang tepat.

Masa ini yang dipandang sebagai sumber pengetahuan hanya apa yang secara alamiah dapat dipakai manusia, yaitu akal (rasio) dan pengalaman (empiri), padahal orang cendrung untuk memberi tekanan pada salah satu dari keduanya, maka pada abad ini timbul 2 aliran yang saling bertentangan, yaitu aliran rasionalisme dan empirisme.

Aliran rasionalisme berpendapat, bahwa sumber pengetahuan yang mencukupi dan yang dapat dipercaya adalah rasio (akal). Hanya pengetahuan yang diperoleh melalui akallah yang memenuhi syarat yang dituntut oleh sifat umum dan yang perlu mutlak, yaitu syarat yang dituntut oleh semua pengetahuan ilmiah.

Aliran empirisme berpendapat bahwa empiri atau pengalamanlah yang menjadi sumber pengetahuan, baik pengalaman batiniah maupun pengalaman yang lahiriah. Akal bukan sumber pengetahuan akan tetapi akal mendapat tugas.

Rasionalisme adalah Rene Descartes atau Cartesius, pandangannya takkan pernah goyah , tentang kebenaran tertinggi pada akal atau rasio manusia. la juga filosof yang tidak puas dengan pemikiran atau filsafat skolastik yang pandangannnya saling bertentangan dan tidak ada kepastian, maka la mengemukakan metode baru yaitu metode keragu-raguan. Jika sesorang yang ragu-ragu terhadap sesuatu maka sangat jelas ia sedang berfikir.

Descartes mulai berfikir keras. la meragukan segalanya, ia meragukan adanya dunia, adanya Tuhan, bahkan adanya dirinya. "Benarkah tuhan ada? Benarkah dunia ada? Benarkah badanku ada?" Akhirnya ia pada kesimpulan ini, bahwa "karena saya ragu, maka saya befikir, karena saya berfikir maka saya ada, karena saya ada maka Tuhan ada, dan orang lainpun ada. Untuk membuktikan hasil pemikirannya di atas bahwa rasionalisme sangat utama, Descartes mengemukakan metode keragu-raguan, jika orang ragu-ragu terhadap sesuatu, dalam keragu-raguannya itu, jelas ia sedang berfikir, ia juga berpendapat bahwa apa yang harus dipandang sebagai yang benar adalah apa yang jelas dan terpilah pilah (clear dan distinctly) harus dipandang sebagai suatu 
kebenaran (apa yang jelas dan terpilah-pilah itu tidak mungkin didapatkan dari apa yang berada di luar kita, akan ragu-ragu, atau akan berfikir oleh karena akan berfikir, maka akan ada (cogito ergo sum), demikianlah filsafat yang pertama (premium philosophicum) yang dijadikan semboyan oleh Descartes.

Pemikirannya membuat sebuah revolusi falsafi di Eropa karena pendapatnya yang revolusioner bahwa semuanya tidak ada yang pasti, kecuali kenyataan bahwa seorang bisa berfikir. Descartes mencari kebenaran atau sebagai kebenaran, sebab zaman itu yang disebut benar adalah kata-kata pejabat baik pejabat Negara, gereja, atau pejabat pendidikan.

Konsep berfikir digunakanya dalam pengertian yang sangat luas, sesuatu yang berfikir menurutnya adalah sesuatu yang meragukan, memahami, mengerti, menegaskan, menolak, berkehendak, membayangkan dan merasakan, karena perasaan ketika muncul dalam mimpi adalah sebuah bentuk berfikir. Karena berfikir adalah esensi dari pikiran, maka pikiran pasti selalu berfikir bahkan ketika sedang tertidur nyenyak.

Rene Descartes pun berfikir demikian ia mengatakan bahwa mempelajari filsafat membutuhkan metode tersendiri agar hasilnya benar-benar logis. la sendiri mendapatkan metode yang dicarinya itu, yaitu dengan menyangsikan segala-galanya atau menerapkan metode keragu-raguan artinya kesangsian atau keragu-raguan ini harus meliputi seluruh pengetahuan yang dimilki termasuk juga kebenaran-kebenaran yang sampai kini dianggapnya sudah final dan pasti.
Bagi Descartes manusia harus menjadi titik berangkat dari pemikiran yang rasional demi mencapai kebenaran yang pasti. Untuk mencapai kebenaran yang pasti maka rasio harus berperan semaksimal mungkin, tidak begitu saja menerima kebenaran atas dasar pancaindera. Pada dasarnya la tetap bersikukuh bahwa semua yang dilihatnya harus diragukan kebenarannya dan setiap yang terlihat jelas dan tegas harus dipilahpilah hingga mendapat bagian-bagian yang kecil.

Atas dasar aturan-aturan itulah, Descartes mengembangkan pikiran filosofonya. Dia sendiri meragukan apakah sekarang sedang berdiri menyaksikan realitas yang tampak di matanya atau sedang tidur dan bermimpi, Sebagaimana ia meragukan dirinya apakah sedang sadar atau sedang gila.

Keraguan ini sangat rasional, karena tidak ada perbedaan signifikan antara kenyataan dalam mimpi dan kenyataan ketika terjaga karena gambarannya sama. Misalnya seseorang bermimpi bertemu dengan kakeknya kemudian ia benar-benar bertemu kakeknya, Apakah yang benar itu ketika tertidur atau terjaga, tidak jelas karena hasilnya tidak ada bedanya.

Kebanyakan filosof sejak Descartes memandang penting teori pengetahuan ini dan sikap mereka ini terutama disebabkan oleh Descartes tentang teori "aku berfikir maka aku ada" membuat pikiran menjadi lebih pasti dari pada materi dan pikiran saya lebih pasti dari pada pikiran orang lain. Makanya semua sifat filsafat yang diturunkan Descartes cendrung pada subyektivisme dan cendrung untuk menganggap materi sebagai suatu hanya bias diketahui dengan cara menarik kesimpulan dari apa yang diketahui pikiran. 
Dalam karya Descartes, ia menjelaskan pencarian kebenaran melalui metode keraguraguan, karyanya yang berjudul $A$ Discours on Methode mengemukakan perlunya memperhatikan empat hal berikut :

1. Kebenaran baru dinyatakan sahih apabila jika telah benar-benar inderawi dan realitasnya telah jelas dan tegas, sehingga tidak ada suatu keraguan apapun yang mampu merobohkannya.

2. Pecahkanlah setiap kesulitan atau masalah itu sampai sebanyak mungkin sehingga tidak ada suatu keraguan apapun yang mampu merobohkannya.

3. Bimbinglah pikiran dengan teratur dengan memulai dari hal yang sederhana dan mudah diketahui secara bertahap sampai pada yang paling sulit dan kompleks.

4. Dalam proses pencarian dan pemeriksaan hal-hal sulit selamanya harus dibuat perhitungan-perhitungan yang sempurna dan pertimbangan yang menyeluruh sehingga diperoleh keyakinan bahwa tidak ada satupun yang mengabaikan atau ketinggalan dalam penjelajahan itu.

Descartes memulai filsafat dari metode, metode keraguan itu bukanlah tujuannya. Tujuan metode ini bukanlah untuk mempertahankan keraguan. Sebaliknya metode ini bergerak dari keraguan itu sendiri untuk menuju kepastian. Keraguan Descartes hanya ditujukan untuk menjelaskan perbedaan sesuatu yang dapat diragukan dan sesuatu yang tidak dapat diragukan.

Kebenaran yang dihasilkan oleh rasio tetap diambang keraguan, agar terbebas dari yang meragukan, akhir dari pencarian kebenaran dan sebagai awal menyelidikinya, kebenaran harus melibatkan Tuhan.

Yang paling fundamental dalam mencari kebenaran adalah senantiasa merujuk kepada prinsip Cogito ergo sum (saya berfikir maka saya ada), karena keyakinan dalam diri sendiri, kebenaran lebih terjamin dan terjaga. Dalam diri sendiri terdapat tiga ide bawaan saya sejak lahir, yaitu :

1. Pemikiran; sebab saya memahami diri saya sebagai makhluk berfikir, harus diterima bahwa juga bahwa pemikiran merupakan hakekat saya.

2. Allah sebagai wujud yang sama sekali sempurna; karena saya mempunyai ide sempurna, mesti ada suatu penyebab sempurna untuk ide itu, karena akibat tidak bisa melebihi penyebabnya, wujud yang sempurna itu tidak lain daripada Allah.

3. Keluasan; saya mengerti materi sebagai keluasan atau eksistensi sebagaimana hal ini dilukiskan dan dipelajari oleh ahli ilmu ukur.

Descartes juga telah mencari hakikat sesuatu, akan tetapi agar hakikat segala sesuatu dapat ditentukan maka dipergunakan pengertianpengertian tertentu, yaitu : substansi, atribut atau sifat dasar dan modus.

Substansi adalah apa yang berada sedemikian rupa sehingga tidak memerlukan sesuatu yang lain untuk berada. Substansi yang dipikirkan seperti itu sebenarnya hanya ada satu saja, yaitu Allah. Segala sesuatu yang lain hanya dapat dipikirkan sebagai berada dengan pertolongan Allah. Jadi sebutan substansi sebenarnya tidak dapat dengan cara yang sama diberikan kepada Allah. Hal-hal bendawi dan rohani yang diciptakan memang dapat juga 
dimasukkan ke dalam pengertian substansi itu, dan dalam praktiknya Descartes memasukkan jiwa dan materi dalam pengertian substansi juga.

Pemahaman terhadap substansi di sini penulis mencoba memaparkan memakai bahasa sederhana bahwa substansi ini adalah keberadaan sesuatu tetapi sesuatu tersebut tidak memerlukan pertolongan atau bantuan apapun dan siapapun atas keberadaannya, dan yang termasuk dalam substansi di sini adalah Allah karena Allah merupakan Zat yang tidak memerlukan pertolongan pada sesuatu apapun atas keberadaannya. Namun dalam praktiknya Descartes juga memasukkan jiwa dan materi ke dalam pengertian Substansi juga.

Atribut adalah sifat asasi. Tiap substansi memiliki sifat asasinya sendiri yang menetukan hakekat substansi itu. Sifat asasi ini mutlak perlu dan tidak dapat ditiadakan, sifat asasi ini adanya diandaikan oleh segala sifat yang lain.

Modus adalah segala sifat substansi yang tidak mutlak perlu dan yang dapat berubah. Dari penjelasan tersebut di atas jelaslah bahwa segala substansi bendawi memilki sebagai atribut atau sifat asasi yaitu keluasan dan memiliki sebagai modus (modi) yaitu bentuk dan besarnya yang lahiriyah serta gerak dan perhentiannya. Dengan demikian maka segala benda tidak memiliki ketentuan yang kualitatif, yang menunjukkan kualitas atau mutunya. Seluruh realitas bendawi dihitungkan ke kuantitas atau bilangan. Oleh karena itu segala hal yang bersifat bendawi pada hakekatnya adalah sama, perbedaanperbedaannya bukan mewujudkan hal yang asasi melainkan hanya tambahan saja.

Descartes memandang bahwa manusia sebagai makhluk dualitas (substansi) yaitu jiwa sebagai pemikiran dan tubuh sabagi keluasan. Dia mencontohkan tubuh sebagai mesin dan jiwa menjalankannya. Karena stiap substansi yang satu sama lain saling terpisah dari substansi lain, sudah tentu ia menganut dualism tentang manusia. Kesulitan untuk mengartikan pengaruh tubuh atas jiwa dan sebaliknya. Satu kali ia mengartikan pengaruh tubuh atas jiwa dan sebaliknya. Satu kali ia mengatakan bahwa kontak antara tubuh dan jiwa berlangsung dalam glandula ninealis yaitu sebuah kelenjar kecil yang letaknya di bawah otak akan tetapi, akhirnya pemecahan ini tidak memadai baginya.

Roh atau jiwa memilki sebagai sifat asasinya yaitu pemikiran dan memiliki sebagai modinya yaitu pikiran-pikiran individual, gagasangagasan dan gejala-gejala kesadaran yang lain. Roh atau jiwa pada hakekatnya berbeda dengan benda, sifat asasi roh adalah pemikiran sedang asasi benda adalah keluasan. Roh dapat dipikirkan dengan jelas dan terpilah-pilah, tanpa memerlukan sifat asasi benda. Oleh karena itu secara apriori tiada kemungkinan yang satu mempengaruhi yang lain, sekalipun dalam praktek tampak ada pengaruhnya, jiwa telah memiliki sebagai bawaannya.

\section{KESIMPULAN}

1. Rasionalisme adalah paham yang menganggap bahwa pikiran akal merupakan satu-satunya dasar untuk memecahkan kebenaran yang lepas dari jangkauan indera.

2. Rene Descartes menemukan metode agar hasil dari mempelajari filsafat benar-benar logis yaitu dengan menyangsikan segalagalanya atau menerapkan metode keragu- 
raguan artinya keragu-raguan harus meliputi seluruh pengetahuan yang dimilki.

3. Menurut Descartes akal adalah substansi yang berdiri sendiri dengan istilah aku berfikir maka aku ada (cogito ergo sum), akal itu immaterial. Akal adalah kesadaran dan sifatnya adalah berfikir, sedangkan tubuh adalah bagian dari alam materi. Sifat materi adalah keluasan.

\section{DAFTAR PUSTAKA}

Hadi Wijoyo, Harun, 1980. Sari Sejarah Filsafat Barat, Kanisius, Yogyakarta.

Russel, Betrand, 2007. Sejarah filsafat Barat, kaitannya Dengan Kondisi Sosio Politik Zaman Kuno Hingga Sekarang, diterjemahkan Sigit Jatmiko dkk, judul asli History of western philosophy and its Connection With Political and Social Cireumstances From The Earliest Times to The Present Day, Pustaka Pelajar, Yogyakarta.

Sadali, Ahmad, Mudzakir, 2004. Filsafat Umum, CV. Pustaka setia, Bandung, Cet.II

Sudarsono, 2001. Ilmu Filsafat Suatu Pengantar, Rineka Cipta, Cet.II, Jakarta.

Tafsir, Ahmad, 2008. Filsafat Umum, Akal dan hati Sejak thales, PT.Remaja Rosda Karya, Bandung. 